\section{Moving beyond a Snapshot to Understand Changes in the Well-Being of Native Amazonians}

\author{
Panel Evidence (2002-2006) from Bolivia
}

Ricardo Godoy, Victoria Reyes-García, Clarence C. Gravlee, Tomás Huanca, William R. Leonard, Thomas W. McDade, Susan Tanner, and the TAPS Bolivia Study Team

Sustainable International Development Program, Heller School for Social Policy and Management, Brandeis University, Waltham, Massachusetts 02454-9110, U.S.A. (rgodoy@brandeis.edu)/Institució Catalana de Recerca i Estudis Avançats and Institut de Ciència i Tecnologia Ambientals, Universitat Autònoma de Barcelona, 08193 Bellatera, Barcelona, Spain (Reyes-García)/Department of Anthropology, University of Florida, Gainesville, Florida 32611, U.S.A. (Gravlee)/Centro Boliviano de Investigación y de Desarrollo Socio Integral, Correo Central, San Borja, Beni, Bolivia (Huanca)/Department of Anthropology, Northwestern University, Evanston, Illinois 60208, U.S.A. (Leonard, McDade)/Department of Anthropology, University of Georgia, Athens, Georgia 30602, U.S.A. (Tanner)/ Tsimane' Amazonian Panel Study (TAPS), Correo Central, San Borja, Beni, Bolivia (TAPS Bolivia Study Team). 22 X 08

Forces such as the opening of trade, globalization, multinational corporate resource extraction, urbanization, acculturation, and colonization catalyze economic, ecological, and sociocultural change, which can threaten the well-being and habitat of native Amazonians. Understanding these forces is of paramount importance to improve the well-being of native Amazonians and to foster the conservation of biological diversity, yet most analyses of these forces rely on cross-sectional data. Though adequate to describe the association between variables at one point in time, cross-sectional data do not allow one to estimate changes in well-being over time. We collected data annually during five consecutive years (2002-2006, inclusive) from a foraging and farming society of native Amazonians in Bolivia (Tsimane') to estimate annual rates of change for seven indicators of adult well-being. Indicators encompassed both objective and subjective measures of well-being that included economic, health, psychological, and social dimensions that overlap well with Tsimane' notions of well-being. The annual rate of change in the inflationadjusted (hereafter real) value of food consumption $(+6.35 \%)$, body mass index $(+0.71 \%)$, and incidence of an-

(C) 2009 by The Wenner-Gren Foundation for Anthropological Research. All rights reserved. 0011-3204/2009/5004-0007\$10.00. DOI: 10.1086/ 599983 ger $(-10.40 \%)$ show significant improvements over time, but the annual rate of change in the self-reported number of recent ailments $(+7.35 \%)$ shows a significant deterioration. Trends in other indicators of well-being (smiles, real wealth, social relations) show positive but insignificant rates of change. Results did not vary by sex and were consistent when using other indicators of well-being.

Native Amazonians have a long tradition of contact with outsiders (Ferguson 1990; Milton 1992; Reeve 1994; Stanfield 1998), but the pace and the intensity of contact have increased in the last three decades from macro-level forces (hereafter forces) such as the opening of trade, globalization, extraction of natural resources by multinational corporations, urbanization, acculturation, and colonization (Godoy et al. 2005b; London and Kelly 2007). These forces have the potential to threaten the well-being and the habitat of native Amazonians. Understanding these forces is of paramount importance to improve the well-being of native Amazonians and to foster biological diversity, yet most analyses of how these forces affect native Amazonians have relied on cross-sectional data or on data collected at one point in time (Godoy 2001; Godoy et al. 2005b; Lu 2007). For instance, drawing on crosssectional data from native Amazonian societies, researchers have made inferences about the effect of these forces on the loss of ethnobotanical knowledge (Reyes-García et al. 2005), erosion of health (Coimbra et al. 2002; Santos and Coimbra 1999), dependence on alcohol and cigarettes (Seale et al. 2003; Tavares et al. 2003), loss of crop diversity (Vadez et al. 2004), decline in leisure time (Gross et al. 1979), and spread of sorcery accusations (Shepard 2002). These outcomes could be considered indicators of well-being.

The standard approach serves well to describe a snapshot of well-being at one point in time or to estimate contemporaneous associations between well-being and these forces, but it does not allow one to estimate changes in well-being over time. In fact, reliance on cross-sectional data to infer changes in well-being over time can produce misleading results (Godoy et al. 2009a). A comprehensive assessment of how these forces shape well-being requires attention to (and direct measures of) both the level and the rate of change in well-being. Panel or longitudinal data-repeated formal measures taken over time from the same person, households, or communities - are valuable for studying indigenous peoples experiencing rapid and continuous changes in lifestyle. Panel data are widely used in the health sciences and in many behavioral sciences to study change over the life cycle and secular (i.e., long-run) change, but they are rare in cultural anthropology (Gravlee et al. 2008). ${ }^{1}$ To our knowledge, there are no

1. Until recently, panel data sets in the behavioral sciences were rare in low-income nations. To our knowledge, such panel studies in progress come mainly from economics and are being conducted in India, Ethiopia, and South Africa (Leonard and Godoy 2008). See Gravlee et al. (2008) 
quantitative panel studies in cultural anthropology that estimate annual rates of changes in well-being among native Amazonians or among other indigenous peoples.

Here we use panel data collected annually during five consecutive years (2002-2006, inclusive) from adults in a foraging and farming society of native Amazonians in Bolivia (Tsimane') to estimate the annual rate of change of economic, health, psychological, and social indicators of well-being.

Because well-being includes many dimensions (BiswasDiener, Vitterso, and Diener 2005; Diener and Suh 2000), we measured economic, health, psychological, and social dimensions of well-being rather than only one dimension of wellbeing. Besides providing a more comprehensive view of wellbeing, the use of different dimensions allows one to assess whether the dimensions move in unison over time. We rely on self-reported measures and on objective measures taken by researchers because annual rates of change of indicators might differ depending on who defines well-being (Ezzati et al. 2006; Izquierdo 2005). It is possible that only some indicators of well-being improve over time, and it is also possible for indicators of well-being measured objectively to move in one direction while subjective indicators of well-being move in another direction.

We analyzed indicators in four categories. Economic indicators included the inflation-adjusted (or real) monetary value of a person's weekly consumption of 18 food items and the real monetary value of a person's wealth in 22 modern and traditional physical assets. We use the convention from economics of using the word "real" to refer to inflationadjusted monetary values. Health indicators included the body mass index (body weight in $\mathrm{kg} /$ standing height in $\mathrm{m}^{2}$ ) at the time of the interview and self-reported recent illness history (number of ailments during the 14 days before the day of the interview). Psychological indicators included the incidence of smiling during the interview and self-reported incidence of anger during the 7 days before the day of the interview. We also analyzed a social indicator, the frequency of traditional drinking during the 7 days before the day of the interview. Below we discuss how we gather indicator data, but first we explain two reasons for selecting these indicators.

First, researchers have used some of these indicators in crosscultural studies of well-being (Biswas-Diener, Vitterso, and Diener 2005; Diener and Suh 2000; Gough and McGregor 2007), so in using these indicators, we make it easier to compare results from the Tsimane' with the results from other societies.

Second, the indicators overlap well with Tsimane' notions of well-being. During 2002-2003 we collected information on what made adult Tsimane' happy. Elsewhere (Brabec et al. 2007; V. Reyes-García, R. Godoy, T. Huanca, W. Leonard, T. McDade, S. Tanner, V. Vadez, M. Martinez-Rodriguez, and the TAPS Bolivia research team, unpublished manuscript) we describe

for examples of panel studies in the health and behavioral sciences and a fuller discussion of the potential benefits and limitations of panel studies in cultural anthropology. the methods use to elicit and analyze those data. Among the top 10 reasons for being happy, Tsimane' listed sharing leisure time with kin and friends, having enough food to eat, enjoying good health, and owning commercial goods. Our choice of outcomes-food consumption, wealth, anthropometric indicators of short-run nutritional status, perceived health, and drinking traditional beverages-overlap well with what matters most to Tsimane' when they think about well-being.

\section{Specific Aims}

We have three aims that relate to methods, theory, and public service. First, we want to describe the rate of change in indicators of well-being while controlling for a wide range of confounders. This might sound pedestrian, but when we consider the paucity of rigorous quantitative analysis in cultural anthropology of changes over time in well-being in general and in well-being among native Amazonians in particular, then reporting empirical data first allows researchers the opportunity to examine the data and then decide whether there are puzzles worth explaining in subsequent work.

Our second aim is theoretical. We want to test the "doom and gloom" hypothesis about the presumptive adverse effects of forces such as globalization, the opening of trade, market exposure, acculturation, and the like on native Amazonians. A sample of book titles on development in the Amazon gives away the deep pessimism permeating the field: Victims of the Miracle (Davis 1977), Underdeveloping the Amazon (Bunker 1985), and The Last Forest (London and Kelly 2007). We are mindful that here we test the hypothesis using data from only one ethnic group. Annual rates of change in indicators of well-being will undoubtedly vary across space, time, and cultures (Biswas-Diener, Vitterso, and Diener 2005).

Our third aim has to do with public service to anthropology and other academic disciplines. The TAPS team has put the complete panel data set and its documentation, along with publications from the long-term research project, on this Web site for the general public: http://people.brandeis.edu/ rgodoy/. In so doing, we break ranks with a long-established tradition in cultural anthropology of treating field data as a private possession, and we make it available to the general public so they can challenge our findings or test hypotheses and explore topics beyond the ones we have explored.

\section{Background: The People, the Context, and the Study}

\section{The People}

The Tsimane' number about 8,000 people, and they live in about 100 villages, mostly along the Maniqui and the Apere rivers in the department of Beni. According to one study (Reyes-García 2001) that drew on population estimates from the 1970s onward, the Tsimane' population has grown at an annual rate of $4.76 \%$ owing to a high fertility rate and a decline in mortality (Gurven, Kaplan, and Supa 2007). Ongoing anal- 
ysis of satellite imagery suggests that the main territory of the Tsimane' covers $3,451 \mathrm{~km}^{2}$. The Tsimane' economy centers on hunting, fishing, plant foraging, and slash-and-burn farming. Elsewhere we provide an overview of Tsimane' ethnography and history (Huanca 2008) and document their economic self sufficiency and low level of monetary income ( US\$1-\$2/day/ person; Godoy et al. 2007a).

\section{The Context}

Two factors make it difficult to predict trends in well-being among the Tsimane'. First, the years 2002-2006 saw many socioeconomic changes in the Tsimane' territory. Some of the changes likely improved indicators of well-being, but others likely eroded indicators of well-being, producing an ambiguous net effect on well-being. On the positive side, coverage of public health services (e.g., vaccination, water wells) increased (Gurven, Kaplan, and Supa 2007). Several nongovernment organizations entered the area during 2002-2006 to improve farm productivity, health, sanitation, and the sustainable extraction of a wild forest thatch palm in demand by national and international buyers. In 2006, the government started paying parents to send their children to school and introduced solar panels and audiovisual equipment to rural schools to facilitate night classes for adults. Many villagers have gained access to motorized canoes, so river travel has become easier and more popular. On the negative side, 2002-2006 continued to see encroachment into the Tsimane' territory by cattle ranchers, logging firms, and colonist farmers. Encroachers bring employment, new production technologies, and modern medicines, but they usurp land, deplete timber species and animal wildlife, and spur conflict (Godoy et al. 1998). Town traders with better access to information about markets and prices continue to ply the rivers and comb through the Tsimane' territory supplying commercial goods (including alcoholic beverages) and credit in exchange for farm and forest products. These exchange transactions may be unfair to the Tsimane' and force them into unwanted debt servitude. One of the worst floods in the last two decades hit the Tsimane' territory in 2006; the flood triggered international food aid into the area (Qureshi 2007).

Besides socioeconomic forces pushing in opposite directions, the second factor that makes it hard to predict the rate of change in indicators of well-being has to do with the effectiveness of the traditional cultural tapestry in protecting Tsimane' well-being. Analysis of the secular trend of adult standing physical stature and of ethnobotanical knowledge of useful plants suggests no significant secular change in the two outcomes among Tsimane' born between the 1920s and 1980-1985 (Godoy et al. 2006a, 2009a; Gurven, Kaplan, and Supa 2007). These studies hint at the idea that the persistence of local culture, local language, and local forms of social capital might protect Tsimane' from some adverse shocks (Godoy et al. 2007b). Indeed, recent analyses have documented positive associations between a mother's level of ethnobotanical knowledge and the health of her children. Nevertheless, we also find that weather perturbations during gestation, birth year, and the first 2 years of life are associated with lower standing physical stature of adult women and of boys 2-12 years of age, suggesting that the traditional cultural tapestry might not protect in full the long-run nutritional status of all Tsimane' (Godoy et al. $2008 a, 2008 c)$.

\section{The Study}

We draw on survey data from a panel study in progress that started in 2002 (Leonard and Godoy 2008) in 13 Tsimane' villages along the Maniqui River, department of Beni. We spent 1995-2001 doing pilot or background studies among the Tsimane' to identify villages for the panel study, to gain the trust of study participants, and to refine methods of data collection. The formal panel available to the public started in 2002, and the data presented in this article were gathered annually during June-September from all Tsimane' in the 13 villages. During 2006 we tracked "attriters" who had moved to a remote village that was not part of the panel study. We selected the 13 villages to capture geographic variation in closeness to the market town of San Borja (mean $=25.96$ $\mathrm{km} ; \mathrm{SD}=16.70$ ), the only town along the Maniqui River. In capturing variation to the market town we tried to capture variation in some of the underlying forces (e.g., market exposure) affecting the Tsimane'. We cannot assess how representative the 13 villages of the panel study are of all Tsimane' villages, but our impression is that they are fairly representative and certainly capture the range of variation in variables such as population size, closeness to market town, and economic activities.

The panel includes a total of about 1,500 people, but the sample used in this article ( 355 women, 353 men) contains only people over the age of 16 (or younger if they headed a household) because we excluded children and young adults when measuring economic and psychological indicators of wellbeing.

We collected annual data during a visit to the village that lasted several consecutive days. We reserved most of those days for interviews, but we also set aside at least 1 day to take anthropometric measures from all villagers in the village school. Interviews lasted about one hour/adult and took place in the home of the participant. Four Bolivian university graduates conducted the survey and four Tsimane' who worked in the study from its inception served as translators.

\section{Variables}

\section{Outcome Variables}

We measured food consumption at the household level by asking the female head of the household about the quantity of 18 different food items consumed by the household during 
the 7 days before the day of the interview. The 18 food items covered a diverse selection of foods regularly eaten by Tsimane', giving us a fairly reliable indicator of nutritional coverage. The 18 items included foods bought in the market (e.g., cooking oil), common crops grown by Tsimane' (e.g., manioc), game, fish, and meat and other products from domesticated animals (e.g., eggs). These food items have been used in other nutritional studies in rural Latin America (DeWalt 1983; Leonard et al. 1993, 1994). We multiplied the quantity of the food consumed by the village price of the food to arrive at the nominal monetary value for each food item. For food items produced in the village, we used the selling price in the village, and for food items bought in the market we used the buying price in the village. If the village lacked a price for a food item, we imputed the price from the one used in the nearest village. We added the value of the 18 food items to arrive at the total value of food consumption for a household and divided the total value by the number of people in the household. ${ }^{2}$ We did not use adult equivalents to estimate the value of food consumption for a person because of random measurement errors with age (Godoy et al. 2008b).

We measured wealth by adding the nominal monetary value of five traditional physical assets (e.g., canoes, bows), 13 modern physical assets (e.g., radios, cutlasses), and four domesticated animals (e.g., chickens, ducks) owned by the adult. Based on ethnographic knowledge of the Tsimane', we selected a range of physical assets to capture wealth differences in the entire sample and between women and men. For instance, the poorest people own bows, arrows, and small domesticated animals (e.g., chickens), but better-off people are more likely to own large domesticated animals (e.g., cattle) and expensive industrial goods (e.g., guns). Among the assets that we measured were assets that women generally own (e.g., bags, pots, small domesticated animals), and assets that men generally own (e.g., cattle, guns). We multiplied the quantity of the asset by the selling price of the asset in the village to estimate the value of that asset, and added the value of the different assets to arrive at a monetary measure of total wealth for the person. We followed the same imputation technique for missing prices of assets as we did for missing prices of foods.

To calculate BMI, we followed the protocol of Lohman, Roche, and Martorell (1988) and measured and weighed people in light clothing, without shoes or hats. We used a portable stadiometer to measure height, which we recorded to the nearest millimeter, and we used a Tanita Digital scale to measure body weight, which we recorded to the nearest $0.20 \mathrm{~kg}$.

To calculate self-reported recent illness history, we asked people to report all the illnesses they had experienced during

2. In several publications (e.g., Godoy et al. 2006c, 2007b), we tested for intrahousehold disparities in anthropometric indicators of nutritional status and food consumption between girls and boys or women and men and generally found little evidence for such disparities, suggesting that mean measures of food consumption per person are probably accurate reflections of actual food consumption per person. the 2 weeks before the day of the interview, and added the number of different illnesses. Responses included a mix of illness proper and symptoms of illness.

During the interview, surveyors noted whether the person smiled or remained somber. In the analysis, the smile variable took the value of 1 if the person laughed during the interview and 0 if the person neither smiled nor laughed, or only smiled. Elsewhere (Godoy et al. 2005a, 2006b, 2009b) we review the cross-cultural literature showing the validity of smiles as a reliable marker of mirth. ${ }^{3}$

To measure self-reported anger, we asked people how often they had been angry during the 7 days before the day of the interview. For the analysis, we coded the variable as 1 if the person had experienced one or more episodes of anger and 0 if the person had not experienced anger. ${ }^{4}$

Finally, we asked people how often they had consumed chicha during the 7 days before the day of the interview. Chicha is the traditional home-brewed beverage among native Amazonians. Made from crops such as manioc, plantains, or maize, chicha is generally drunk in a group and is the preferred way through which native Amazonians share experiences with each other and enjoy each other's company (Overing and Passes 2007; Godoy et al. 2009b). Unfortunately, we did not ask whether people had consumed chicha in a group or alone. ${ }^{5}$

\section{Explanatory Variables}

To estimate the annual rate of change we include a variable for the survey year. Control variables include the person's age in years and the maximum school grade attained by the person at the time of each survey, household size measured with a head count of all people living in the household at the time of the annual survey, average amount of monthly rain during

3. The Tsimane' word for smile or laughter, dyisi, connotes happiness or to make fun of someone. Tsimane' often sit in a circle quaffing beverages made from fermented manioc or maize or from commercial alcohol. At those times they make jokes, triggering smiles and loud laughter. Tsimane' believe that a married man should not laugh openly in front of a married woman, and vice versa. A pregnant women and the father should not laugh, smile, or make fun of a person with a disability because the fetus, when born, might acquire the disability. Tsimane' say one should not smile in front of strangers because the smile might allow the stranger to bewitch the person who smiles. One myth tells of a time when there was no sun and when a taboo proscribed women from smiling. Worms filled the vagina of women who broke the taboo.

4. Tsimane' distinguish between several types of anger and display it in different ways. The word fudyi'dyi'dye' refers to the annoyance a husband feels when his wife does not make the traditional fermented (chicha) beverage to welcome him back after a long hunting trip. The words facoi' or facoijdye connote open displays of rage and apply to fractious people before a brawl. A milder form of anger, fara'naqui, refers to people using scurrilous language, grousing at a misfortune, or sulking after receiving criticism. Besides raising their voice and fighting, Tsimane' display anger through subtle body movements, such as how they sit or spit or how they hold a drinking gourd (Godoy et al. 2009).

5. Sometimes people will consume chicha alone; for instance, a person might consume chicha before going to the fields. 
the year, and a full set of dummy variables for villages $(n=13-1=12)$. We include rain because climate affects mood (Keller et al. 2005). Village dummy variables control for village attributes that remain fixed during 2002-2006 (e.g., village-to-town distance).

The following variables were transformed into natural logarithms to facilitate their interpretation: food consumption, wealth, rain, BMI, self-reported recent illness history, and chicha drinking. We added +1 to illness and chicha drinking because $27.34 \%$ of the sample did not report an illness and $63.98 \%$ of the sample had not consumed chicha. ${ }^{6}$ Current nominal values for food consumption and for wealth were transformed into real values using the consumer price index for agricultural and natural resources of Bolivia.

\section{Measurement Error and Attrition}

The chief explanatory variable-year of survey-contains no random or systematic measurement error (Godoy et al. $2008 b$ ), but some of the outcome variables contain random and systematic measurement error. Consumption and wealth contain measurement errors from price imputation (Deaton 1997) and from faulty recall. Body weight and standing height had rounding errors (Godoy et al. 2006a). We cannot assess if self-reported measures of recent illness history, food consumption, anger, and drinking chicha contain random measurement errors, though they likely contain biases from forward telescoping (Godoy et al. 2008b). ${ }^{8}$

During the first year of the panel (2002) we surveyed 552 adults (283 women, 269 men), of whom 35, or $6.34 \%$, left permanently after the first survey. Of the initial sample, $62.32 \%$ remained in the panel for the 5 years. The remaining 173 people, or $31.34 \%$, of the sample were present during two to four annual surveys. Below we assess whether permanent attrition biases results.

6. By adding +1 , we avoid losing observations with values of 0 when transforming original values into natural logarithms.

7. The deflators come from the Unidad de Análisis de Políticas Sociales y Económicas (UDAPE), a policy analysis bureau of the Bolivian government. The information was downloaded on March 3, 2008 from the UDAPE Web site http://www.udape.gov.bo/ (table 1.1.5; Deflactores implícitos del PIB por rama de actividad económica). The deflators (base $=1990)$ were $2002=222.23,2003=231.50,2004=257.70$, $2005=235.14$, and $2006=247.85$.

8. We found evidence of bias from forward telescoping with monetary income. We elicited data on income by asking for the amounts of monetary earnings during the 7 days before the day of the interview and then asking the same question for the 8-14 days before the day of the interview. Mean values for the 7 days before the day of the interview tended to be significantly higher than mean values for the 8-14 days before the day of the interview. We also found evidence of forward telescoping with some measure of self-perceived illness. It is therefore possible that forward telescoping also affects other outcomes used in this article (e.g., chicha drinking, food consumption), though we have no way of testing the idea (Godoy et al. 2008c).

\section{Analysis}

We used linear regressions with individual fixed effects, clustering by person, and robust standard errors. We controlled for individual fixed effects to remove attributes of the person that remained fixed during the study period, which could affect results. For instance, suppose that some people had unmeasured but relatively stable personality traits (e.g., drive, inquisitiveness) that induced them to change their well-being during the period under study. Failure to control for traits that remained stable would bias the estimated annual rate of change of the indicators. We cannot correct for all endogeneity biases, so results must be read as associations. For the statistical analysis we used Stata for Windows, version 10 (Stata, College Station, TX).

\section{Results}

\section{Main Results}

Table 1 suggests that during 2002-2006, Tsimane' experienced significant improvement in three of the seven indicators of well-being. The monetary real value of food consumption increased by $6.35 \% /$ year $(P=0.001$; col. 1$)$. The BMI improved by $0.71 \% /$ year $(P=0.001$; col. 3$) .{ }^{9}$ Previous research among the Tsimane' suggests that their BMI falls within the healthy range (Godoy et al. 2005b). During the last year of the panel data used in this article (2006), men and nonpregnant women in the sample had an average BMI of 23.56 and 23.69, respectively. Given these BMI values, higher levels of BMI indicated better short-run nutritional status. The annual growth rate in BMI of $0.71 \%$ implies that, if continued and if all else remains constant, in a decade, on average, Tsimane' men will have a BMI of 25.29 and Tsimane' women will have a BMI of 25.43, near the upper limit of the range of recent recommendations of a healthy BMI (Brabec et al. 2007). The incidence of anger declined during the study period; the passage of each year lowered the probability of reporting anger by $10.40 \%(P=0.001$, col. 6$) .{ }^{10}$ Only with self-reported recent illness history did we find a decline in well-being. During 2002-2006, the self-reported number of ailments during the 14 days before the day of the interview increased by $7.35 \% /$ year $(P=0.001$, col. 4$)$.

Indicators of well-being that showed positive but statistically insignificant rates of change or improvement included the in-

9. It is customary when using BMI as an outcome variable to run separate regressions for women and men. The use of an individual fixed effect model removes the confounding role of sex. That said, we reestimated the regression of column 3, table 1, separately for women and for men and found annual rates of change of $0.855 \%(P=0.001)$ for men and $0.56 \%(P=0.011)$ for women.

10. In this article and elsewhere (Godoy et al. 2009), we found no significant socioeconomic predictor of anger. The results of table 1 suggest that only rainfall bears an association with anger. The coefficient of the logarithm of rain implies that an increase of $1 \%$ in the mean amount of monthly rain during the year was associated with an increase of $0.17 \%$ $(P=0.001)$ in the probability of reporting anger. 
Table 1. Annual rate of change in economic, health, psychological, and social indicators of well-being among Tsimane' adults $>16$ years of age during 2002-2006 (inclusive)

\begin{tabular}{|c|c|c|c|c|c|c|c|}
\hline \multirow[b]{2}{*}{ Explanatory variables measured annually } & \multicolumn{2}{|l|}{ Economic } & \multicolumn{2}{|c|}{ Health } & \multicolumn{2}{|c|}{ Psychological } & \multirow{2}{*}{$\frac{\text { Social }}{\text { 7. Chicha }}$} \\
\hline & 1. Food consumption & 2. Wealth & 3. BMI & 4. Illness & 5. Smile & 6. Anger & \\
\hline Annual rate of change (year of survey) & $.063^{* *}$ & .006 & $.007^{* *}$ & $.073^{* *}$ & .008 & $-.104^{* *}$ & .020 \\
\hline Age (in years) & .001 & .0009 & -.0004 & $.005^{*}$ & .001 & .001 & .005 \\
\hline Schooling (maximum grade finished) & -.001 & .012 & -.001 & .006 & -.0002 & .005 & .005 \\
\hline Log of household size (head count) & $-.406^{* *}$ & -.027 & .0003 & -.009 & -.011 & -.003 & -.058 \\
\hline Log of BMI & -.147 & $.400^{* *}$ & $\mathrm{x}$ & $\mathrm{x}$ & -.121 & .110 & .328 \\
\hline Log of standing height & -.410 & .471 & $\mathrm{x}$ & .943 & 1.310 & .055 & -.265 \\
\hline Log of wealth of 22 physical assets & .036 & $\mathrm{x}$ & $.013^{* *}$ & .048 & .023 & -.035 & .034 \\
\hline Log of illness (no. self-reported ailments) & .044 & .029 & $-.012^{* *}$ & $\mathrm{x}$ & -.015 & .003 & .038 \\
\hline Log of annual mean monthly rain & $-.257^{* *}$ & $-.236^{* *}$ & .0005 & $-.406^{* *}$ & $.166^{*}$ & $.175^{* *}$ & -.136 \\
\hline$R^{2}$ overall & .227 & .017 & .014 & .027 & .003 & .040 & .008 \\
\hline Sample & 2,225 & 2,238 & 2,085 & 2,238 & 2,231 & 2,238 & 2,238 \\
\hline
\end{tabular}

Note. Results of individual fixed-effect linear panel regressions. Data in columns 1-4 and 7 are natural logarithms (cols. 1 and 2 show natural logarithms of real monetary value); data in columns 5 and 6 are dichotomous variables. Regressions include robust standard errors, clustering by subject, constant (not shown), and a full set of village dummy variables (not shown). Column 3 excludes pregnant women. BMI $=$ body mass index, and $\mathrm{x}$ indicates the variable was intentionally left out. Column 4 refers to self-perceived recent illness history, or total number of self-reported ailments experienced during the 14 days before the day of the interview.

*Significant at $5 \%$.

${ }^{* *}$ Significant at $<1 \%$.

cidence of smiles, the value of real wealth, and the frequency of drinking chicha. The passage of each year increased the probability of smiling by $0.82 \%(P=0.594$, col. 5$)$. Real wealth increased by $0.63 \% / y e a r(P=0.444$, col. 2$)$ and the frequency of drinking chicha increased by $2.05 \% /$ year $(P=0.097)$.

\section{Heterogeneity}

We tested for interaction effects to assess whether results varied by sex or by schooling and found no evidence of heterogeneity within the sample. The annual rates of change just discussed applied to women and to men, to the schooled and to the unschooled.

Nevertheless, we found that annual rates of change varied by closeness to town, with people living above the median village-to-town distance (far) having slightly lower rates of improvement in indicators of well-being than people living nearer to town. People in more remote villages had an annual rate of change in the number of self-reported ailments that was $+0.003 \%(P=0.025)$ higher than the annual rate of change in the number of self-reported ailments among people living nearer to the market town. People living in more remote villages were $0.01 \%$ /year $(P=0.001)$ less likely to smile and $0.004 \%$ / year $(P=0.020)$ more likely to report anger than their peers living closer to town. Though statistically significant at the $95 \%$ confidence level or higher, the magnitude of the difference in rates of change between people living far and near the town is small, suggesting that improvements in well-being apply to most adult Tsimane' in the sample.

\section{Attrition Bias}

We assessed whether there was something special about people who had left the panel study after the first survey of 2002 . To do so, we regressed the outcomes of table 1 against all the explanatory variables of table 1 but $(a)$ used only the first year (2002) of data, (b) excluded the year variable since we only had observations for 1 year, and $(c)$ added an explanatory dichotomous variable for permanent attriters. The dichotomous variable for attriters took the value of 1 if the person was present only in 2002, and it took the value of 0 if the person was present in the 2002 survey and at least one other survey. In regressions whose results we do not show, we found that the dichotomous variable for the permanent attriter was not significantly related to any indicator of well-being at the 95\% confidence level or higher. From this we conclude that permanent attrition is probably more random than informative and therefore unlikely to bias the coefficients of table 1 .

\section{Extensions}

Could the main results reflect our choice of indicators? To answer the question, we removed the outcome variables from table 1 and replaced them with the following new outcome variables for economic, health, psychological, and social indicators of well-being: (1) natural logarithm of monetary real income earned during the 2 weeks before the day of the interview (economic), (2) natural logarithm of the sum of four skinfolds (triceps, biceps, subscapular, suprailiac; mm) (health), (3) self-reported number of bedridden days during the 2 weeks before the day of the interview (health), (4) number of self- 
Table 2. Annual rate of change in economic, health, psychological, and social indicators of well-being among Tsimane' adults $>16$ years of age during 2002-2006 (inclusive)

\begin{tabular}{|c|c|c|c|c|c|}
\hline \multirow[b]{2}{*}{ Explanatory variables measured annually } & \multirow{2}{*}{$\begin{array}{l}\text { Economic } \\
\begin{array}{l}\text { 1. Monetary } \\
\text { income }\end{array}\end{array}$} & \multicolumn{2}{|c|}{ Health } & \multirow{2}{*}{$\begin{array}{c}\text { Psychological } \\
\text { 4. Fear }\end{array}$} & \multirow{2}{*}{$\begin{array}{l}\text { Social } \\
\text { 5. Credit }\end{array}$} \\
\hline & & $\begin{array}{l}\text { 2. Sum of four } \\
\text { skinfolds }\end{array}$ & $\begin{array}{l}\text { 3. Bedridden } \\
\text { days }\end{array}$ & & \\
\hline Annual rate of change (year of survey) & $.053^{*}$ & $.055^{* *}$ & $.053^{* *}$ & $-.061^{* *}$ & $.212^{* *}$ \\
\hline Age $(y r)$ & .008 & .0004 & .008 & -.003 & $.007^{* *}$ \\
\hline Schooling (maximum grade finished) & $.056^{*}$ & -.009 & -.001 & .025 & -.001 \\
\hline Log of household size (head count) & .006 & $.044^{* *}$ & -.029 & -.028 & $-.073^{* *}$ \\
\hline Log of body mass index & .238 & $\mathrm{x}$ & $\mathrm{x}$ & -.088 & .099 \\
\hline Log of standing height & .896 & $\mathrm{x}$ & 2.070 & -1.075 & $2.801^{* *}$ \\
\hline Log of wealth of 22 physical assets & $\mathrm{x}$ & -.011 & .039 & -.032 & .011 \\
\hline Log of illness (no. self-reported ailments) & -.012 & .027 & $\mathrm{x}$ & -.043 & $.101^{* *}$ \\
\hline Log of annual mean monthly rain & $-.370^{* *}$ & $-.132^{* *}$ & .034 & .046 & $-.352^{* *}$ \\
\hline$R^{2}$ overall & .015 & .011 & .009 & .001 & .174 \\
\hline Sample & 2,253 & 2,079 & 2,240 & 2,238 & 2,232 \\
\hline
\end{tabular}

Note: Results of individual fixed-effect linear panel regressions with additional indicators of well-being. Table 1 notes apply here, but outcome variables differ. 1 = sum of monetary real income from sale of goods and wage labor earned during the 14 days before the day of the interview; 2 = sum of triceps, biceps, subscapular, and suprailiac; $3=$ total number of self-reported bedridden days during the 14 days before the day of the interview; 4 = person experienced at least one episode of fear during the 7 days before the day of the interview $(1=$ yes; $0=$ no); and $5=$ self-perceived access to credit in an emergency $(1=$ yes; $0=$ no).

"Significant at $5 \%$.

${ }^{*}$ Significant at $<1 \%$.

reported feelings of fear during the week before the day of the interview (psychological), and (5) self-perceived access to credit in case of an emergency (social).

The results of the additional analysis, shown in table 2, confirm the results of table 1 . The results of table 2 show that real monetary income improved by $5.32 \% /$ year $(P=$ $0.027)$ and skinfolds improved by $5.50 \% /$ year $(P=0.001)$, stronger annual rates of change than we found in table 1 with real wealth $(0.63 \%, P=0.444)$ or with BMI $(0.71 \%$, $P=0.001)$. In table 2 we see that the number of selfreported bedridden days increased by $5.39 \%$ /year $(P=$ $0.006)$, below the rate of change in the number of selfreported recent ailments in table $1(+7.35 \% /$ year, $P=$ 0.001 ) but pointing in the same direction of worse selfreported health. The incidence of self-reported fear declined; the passage of each year lowered the probability of reporting fear by $6.19 \%(P=0.001)$, a more modest rate of improvement than we found with anger $(10.40 \% /$ year, $P=0.001)$ but, again, pointing in the same direction; with fear, as with anger, the passage of time was associated with lower probabilities of reporting these negative emotions. Last, selfreported access to credit in a future emergency increased; the passage of each year increased the probability by $21.28 \% /$ year $(P=0.001)$ of reporting having access to credit in an emergency. ${ }^{11}$ In sum, the main results indicating an im-

11. We tested whether access to credit undermined chicha drinking by reestimating column 7 , table 1 , with the credit variable added as an explanatory variable (regression not shown). We found that access to credit bore a positive though statistically insignificant association with chicha drinking in the regression (coefficient for credit $=+0.033$, $P=0.218$ ) and that the annual rate of change of chicha drinking declined provement in many indicators of well-being do not hinge on how we measured the indicators; results stood up relatively well to other definitions of well-being.

We did one additional piece of analysis. To estimate the real value of food consumption and wealth (cols. 1 and 2, table 1), we took out the deflators of the Bolivian government and instead used deflators from the International Monetary Fund (IMF). ${ }^{12}$ With the new deflators, the rate of change in the real value of food consumption fell from $6.35 \%$ year $(P=0.001)$ in table 1 to $5.20 \% /$ year $(P=0.017)$ in the new regression (not shown), and the rate of change in the real value of wealth fell from $+0.63 \% /$ year $(P=0.444)$ in table 1 , to $-18.62 \% /$ year $(P=0.001)$ in the new regression (not shown). These results then suggest that the annual rate of change in economic indicators (particularly wealth) — but not in the other indicators of well-being - is sensitive to the deflator used.

\section{Discussion and Conclusions}

\section{Methodological Contribution}

Two points on methods merit discussion. First, the use of the panel and a multivariate approach allowed us to estimate rates of change in indicators of well-being while controlling for many confounders, including attributes that remained fixed in the person during the study. Together, the panel and a

from $2.05 \%(P=0.097)$ in table 1 to $1.25 \%(P=0.347)$ after adding the credit variable.

12. The deflators from the International Financial Statistics (International Monetary Fund) are $2002=100,2003=103.34,2004=$ 107.92, $2005=113.75$, and $2006=118.62$. 
multivariate approach allow us to move beyond naive estimates of change and obtain more precise estimates of change over time. Second, the results confirm the importance of measuring indicators of well-being through self-reported and objective measures, because they have the potential of telling different stories. Using health as an outcome, we saw that the self-reported number of recent ailments and the self-reported number of bedridden days during the 14 days before the day of the interview increased during 2002-2006, suggesting worse self-perceived health. Nevertheless, we also saw that anthropometric measures of short-run nutritional status (BMI and sum of four skinfolds) improved during the same period. One fruitful line of research for future users of TAPS data has to do with estimating rates of change in indicators of well-being while controlling for baseline conditions. For example, our data allows researchers to examine how individual, household, or parental socioeconomic attributes at time $t$ might influence subsequent annual rates of change for the individual, household, or offspring.

In stressing the importance of panel data, we do not mean to belittle the importance of ethnographic work. No amount of statistical sophistication can explain why and how explanatory variables affect outcomes. Ethnography adds blood and flesh to the statistical associations, but blood and flesh without a solid structure of statistical associations-without something to explain, so to speak-leads nowhere. Before explaining why and how things happened, there should be strong proof that things, in fact, happened.

\section{Describe the Rate of Change in Indicators of Well-Being (Aim 1)}

During 2002-2006, three of the seven indicators of well-being that we measured improved significantly, one showed a deterioration, and the remaining three indicators showed improvements, albeit statistically insignificant improvements. The period 2002-2006 saw an increase in the real value of food consumption and an increase in BMI, a decrease in the frequency of self-reported anger, and an increase in the number of self-reported ailments. The main findings remained after introducing other definitions of well-being. Rates of change applied to all Tsimane', not just to women, men, the schooled, or the unschooled, though people living farther from town had slightly lower rates of improvements than people living closer to town. Recall from the earlier discussion that outcome variables likely contain random measurement errors, so the true annual rate of change is probably statistically more significant than our estimates suggest.

\section{Comparison with Other Studies}

How do Tsimane' fare in economic indicators relative to the rest of Bolivia and other indigenous people? The latest estimates from Bolivia's National Institute of Statistics suggest that during 2001-2006, the real GDP/person in Bolivia grew by $1.00 \% / y e a r .^{13}$ This figure lies toward the lower end of our range of estimates for the rate of change in the real value of wealth (0.63\%; table 1$)$ and in monetary real income (5.32\%; table 2). Real per capita GDP for Bolivia is conceptually distinct from our data for the Tsimane, but the comparison suggests that rates of change of two canonical indicators of economic well-being - wealth and income-in the Tsimane' territory probably track general rates of change for economic indicators in the rest of Bolivia. The evidence on rates of change of economic indicators among the Tsimane' meshes with a recent study by the World Bank (Lunde, Skoufias, and Patrinos 2007; Hall and Patrinos 2006), which suggests that between 1997 and 2002 the share of indigenous people living in poverty in Bolivia fell, but by less than one percentage point (Hall and Patrinos 2006). In sum, we cannot say whether the empirical results from the Tsimane' apply to other populations of native Amazonians in Bolivia, but we can say that the modest positive rates of change for wealth and significant rate of change for monetary real income among the Tsimane' mirror the positive (albeit modest) rate of change of economic indicators for Bolivia's indigenous population.

The low and insignificant rate of change for the propensity to smile $(0.82 \%$ /year, $P=0.594)$ dovetails with research from industrial nations suggesting that happiness remains stable despite changes in economic conditions (Di Tella and MacCulloch 2006). Called the Easterlin Paradox after economist Richard Easterlin who first spotted the trend, the stability in happiness might reflect changes in aspirations that arise from changes in economic conditions. Improvements in economic conditions make people happier, but if those improvements also raise aspirations, then the level of selfreported happiness will tend to remain constant.

Studies in the United States suggest that anger may be a stable personality trait and therefore does not change over time (Chang et al. 2002), but we are not aware of any study that examines the secular trend in anger (or of our other negative emotion, fear) in industrial nations, so it is difficult to compare our results with the results of other studies.

The finding that Tsimane' self-perceived health deteriorated meshes with research findings from people in other lowincome nations. Murray and Chen (1992) found that across a range of societies, improvement in economic conditions increased self-reported morbidity. Among the Matsigenka, a native Amazonian society in Peru, Izquierdo (2005) used three different cross-sectional surveys spanning three decades $(1968,1975,1998)$ from one community and found that selfreported indicators of health deteriorated over time. These findings suggest that the results from the Tsimane' of increasingly worse self-reported health over time are not unique to the Tsimane'.

13. Recent figures for Bolivia's economic growth rate come from estimates by UDAPE. See footnote 7 for UDAPE Web address. 
Test of the "Doom and Gloom" Hypothesis (Aim 2)

If we analyze the 12 indicators of well-being in tables 1 and 2, we find little support for the "doom and gloom" hypothesis that life gets worse for native Amazonians. Seven indicators of well-being-real food expenditures, monetary real income, anger, fear, BMI, sum of four skinfolds, and perceived access to credit in an emergency-showed large and statistically significant rates of improvement. Two indicators-smiles, and chicha drinking - showed modest, but statistically insignificant rates of improvement at the $95 \%$ confidence level, though chicha drinking was significant at the $90.3 \%$ confidence level. For one indicator of well-being-real value of wealth-we found ambiguous results, with no significant rate of change in table 1 and significant negative rate of change when using the IMF deflators. Last, only for the two measures of selfreported health - total number of self-reported ailments and total number of self-reported bedridden days during the 14 days before the day of the interview-did we find unambiguous evidence for deterioration in well-being. These empirical results then point to two intriguing questions that we try to answer by way of conclusion: Why are most indicators of well-being improving, and what lies behind the deterioration in self-perceived health? ${ }^{14}$

The improvements in well-being come from variables we did not measure. For example, improvements in anthropometric indicators of nutritional status might come from changes in activity levels, which we did not measure. Changes in economic activities toward a more sedentary lifestyle would increase BMI. It is also possible that improvements in indicators of well-being come from changes in how people define some outcomes. For instance, changes over time in what it means to be angry or fearful could explain the rate of improvement in these indicators. Last, it is possible that the changes come from some of the external forces mentioned in the lead paragraph of the introduction. Unfortunately, our data does not allow us to disentangle what aspect(s) of those forces lies behind the trend. We cannot link the rates of improvement in indicators of wellbeing to the activities of particular nongovernment organizations, market exposure, the opening of trade, the presence of encroachers, or government policies. All we can say is that the bundle of these forces acting jointly bears a positive association with rates of change of many indicators of well-being. Although we might not be able to identify the specific determinants behind the improvements in well-being, we can rule out some explanations, particularly village-level characteristics (e.g., proximity to market town, price of inputs or outputs), fixed traits of the individual, and the many explanatory variables included in tables 1 and 2 .

We discuss two possible explanations for the secular deterioration in self-reported health. Murray and Chen (1992) hy-

14. Even though most of the indicators improved, we cannot say that total well-being improved because the indicators of well-being that deteriorate (self-reported morbidity) might exert a disproportionate weight in the measure of a person's self-perceived assessment of total well-being. pothesized that in low-income nations, self-reported good health deteriorates with improvements in economic conditions because people raise the threshold of what they consider healthy. As economic conditions improve, people change the way they label their health condition; health conditions they had previously viewed as normal might now be labeled as illness. The problem with this interpretation for the Tsimane' is that in tables 1 and 2 we control for individual wealth when estimating the rate of change of self-perceived poor health, so we doubt that changes in definition of health lie behind the results, though it is a theoretical possibility we cannot ignore. A second possible reason has to do with the effect of panel conditioning or of our own study on people's answers to questions about their health. Since we have provided some medicines during the annual survey, run health workshops for villagers, and provided financial support to some Tsimane' requiring hospital care, it is possible that Tsimane' feel they have a stronger claim to ask for medicines and medical help from the TAPS project if they report illness during the annual survey. The problem with this interpretation is that the measures of self-reported poor health remained relatively constant during 2002-2004 and rose only in 2005-2006. For example, 75\% of respondents said they had not been bedridden during the 14 days before the day of the interview during the annual surveys of 2002, 2003, and 2004 , but the share dropped to $64 \%$ in 2005 and to $58 \%$ in 2006. Had the share changed gradually each year, it would have provided stronger evidence for panel conditioning, but a sudden jump in the share of unhealthy people likely suggests that the increase in self-perceived poor health reflects unmeasured, unobserved variables.

Despite the presence of encroachers, the expansion of the market economy, and floods, most of the indicators of wellbeing we measured improved but for reasons that remain unclear and that form the natural basis of the future research agenda. Only panel data allowed us to describe with accuracy rates of change over time. Panel data has great potential for documenting and understanding changes in lifestyle of indigenous populations. We do not want to oversell the benefits of panel data sets and elsewhere we discuss its limitation (Gravlee et al. 2008), but for some tasks, such as estimating developmental change of individuals, there might be no substitute.

\section{Acknowledgments}

Research was financed by grants from the National Science Foundation (NSF; U.S.A.) Cultural and Physical Anthropology programs, the NSF, and the World Bank. The Great Tsimane' Council approved the study. We obtained permission from study participants before enrollment in the study. Thanks to the Gran Consejo Tsimane' for their continuous support throughout this research project and to the anonymous reviewers of Current Anthropology. 


\section{References Cited}

$\rightarrow$ Biswas-Diener, R., J. Vitterso, and E. Diener. 2005. Most people are pretty happy, but there is cultural variation: thi $\rightarrow$ Inughuit, the Amish, and the Maasai. Journal of Happiness Studies 6:205-226.

$\rightarrow$ Brabec, M., R. Godoy, V. Reyes-García, and W. Leonard. 2007. $\mathrm{BMI}$, income, and social capital in a pre-industrial society of the Bolivian Amazon: interaction between relative anc community effects. American Journal of Human Biology 19:459-474.

Bunker, Stephen F. 1985. Underdeveloping the Amazon. Chicago: University of Chicago Press.

$\rightarrow$ Chang, P., D. Ford, L. Meoni, N-Y. Wang, and M. Klag. 2002. Anger in young men and subsequent premature cardiovascular disease: the precursors study. Archives of Internal Medicine 162:901-906.

Coimbra, C., Jr., N. Flowers, F. Salzano, and R. Santos. 2002. The Xavánte in transition: health, ecology, and bioanthro pology in central Brazil. Ann Arbor: University of Michigan Press.

Davis, Shelton H. 1977. Victims of the miracle. Cambridge: Cambridge University Press.

Deaton, A. 1997. The analysis of household surveys: a microeconometric approach to development policy. Baltimore: Johns Hopkins University Press.

$\rightarrow$ DeWalt, K. 1983. Income and dietary adequacy in an agricultural community. Social Science \& Medicine 17:1877-1886.

Diener, E., and E. Suh. 2000. Culture and subjective wellbeing. Cambridge, MA: MIT Press.

$\rightarrow$ Di Tella, R., and R. MacCulloch. 2006. Some uses of happines: data in economics. Journal of Economic Perspectives 20: 25-46.

$\rightarrow$ Ezzati, M., H. Martin, S. Skjold, S. Hoorn, and C. Murray. 2006. Trends in national and state-level obesity in the USA after correction for self-report bias: analysis of health surveys. Journal of the Royal Society of Medicine 99:250-257.

$\rightarrow$ Ferguson, B. 1990. Blood of the Leviathan: western contact and warfare in Amazonia. American Ethnologist 17:237-257.

Godoy, R. 2001. Indians, markets, and rain forests: theory, methods, analysis. New York: Columbia University Press.

$\rightarrow$ Godoy, R., E. Goodman, V. Reyes-García, D. Eisenberg, W. Leonard, T. Huanca, T. McDade, S. Tanner, N. Jha, and the TAPS Bolivia research team. 2008a. Rain, temperature, and child-adolescent height among native Amazonians in Bolivia. Annals of Human Biology 35:276-293.

$\rightarrow$ Godoy, R., T. Huanca, V. Reyes-García, S. Tanner, W. Leonard, T. McDade, and V. Vadez. 2005a. Do smiles have a face value? panel evidence from Amazonian Indians. Journal of Economic Psychology 26:469-490.

$\rightarrow$ Godoy, R., M. Jacobson, J. De Castro, V. Aliaga, J. Romero, and A. Davis. 1998. The role of tenure security and private time preference in Neotropical deforestation. Land Eco nomics 74:162-170.

$\rightarrow$ Godoy, R., W. Leonard, V. Reyes-García, E. Goodman, T.
McDade, T. Huanca, S. Tanner, and V. Vadez. 2006a. Physical stature of adult Tsimane' Amerindians: Bolivian Amazon in the 20th century. Economics and Human Biology 4:184-205. Godoy, R., V. Reyes-García, J. Broesch, I. Fitzpatrick, P. Giovannini, M. Martinez-Rodriguez, T. Huanca, et al. 2009a. Long-term (secular) change of ethnobotanical knowledge of useful plants: separating cohort and age effects. Journal of Anthropological Research 65:51-67.

Godoy, R., V. Reyes-García, E. Byron, W. Leonard, and V. Vadez. $2005 b$. The effect of market economies on the well-being of indigenous people and on their use of renewable natural resources. Annual Review of Anthropology 34:122-138.

$\rightarrow$ Godoy, R., V. Reyes-García, W. Leonard, T. Huanca, T. McDade, S. Tanner, C. Seyfried, and the TAPS Bolivia research team. 2007a. On the measure of income and the economic unimportance of social capital: evidence from a native Amazonian society of farmers and foragers. Journal of Anthropological Research 63:239-260.

Godoy, R., V. Reyes-García, T. McDade, T. Huanca, W. Leonard, S. Tanner, and V. Vadez. 2006b. Does income inequality harm the psyche? anger, fear, and sadness in a pre-industrial economy. Social Science \& Medicine 63:359-372.

$\rightarrow-$. 2006c. Why do mothers favor girls and fathers boys? a hypothesis and test of intra-household girl-boy investment disparity. Human Nature 17:169-189.

$\rightarrow$ Godoy, R., V. Reyes-García, S. Tanner, W. Leonard, T. McDade, and T. Huanca. 2008b. Can we trust an adult's estimate of parental school attainment? disentangling social desirability bias and random measurement error. Field Methods 20:26-45.

Godoy, R., V. Reyes-García, V. Vadez, W. Leonard, and E. Byron. 2007b. How well do foragers protect food consumption? panel evidence from a native Amazonian society in Bolivia. Human Ecology 35:723-732.

Godoy, R., S. Tanner, V. Reyes-García, W. Leonard, T. McDade, M. Vento, J. Broesch, et al. 2008c. The effect of rainfall during gestation and early childhood on adult height in a foraging and horticultural society of the Bolivian Amazon. American Journal of Human Biology 20:23-34.

Godoy, R., E. Zeinalova, V. Reyes-García, T. Huanca, H. Kosiewicz, W. R. Leonard, S. Tanner, and the TAPS Bolivia Study Team. 2009b. Does civilization cause discontentment among indigenous Amazonians? test of empirical data from the Tsimane' of Bolivia. Journal of Economic Psychology (forthcoming).

Gough, I., and J. McGregor, eds. 2007. Well-being in developing countries: from theory to research. Cambridge: Cambridge University Press.

Gravlee, C., D. Kennedy, R. Godoy, and W. Leonard. 2008. Methods for collecting panel data: what can cultural anthropology learn from other disciplines? Journal of Anthropological Research (forthcoming).

Gross, D., G. Eiten, N. Flowers, F. Leoi, R. Lattman, and D. Werner. 1979. Ecology and acculturation among native peoples of central Brazil. Science 206:1043-1050. 
$\rightarrow$ Gurven, M., H. Kaplan, and A. Supa. 2007. Mortality experience of Tsimane' Amerindians of Bolivia. American Journal of Human Biology 19:376-396.

Hall, G., and H. Patrinos. 2006. Indigenous peoples, poverty and human development in Latin America. London: Palgrave Macmillan.

Huanca, T. 2008. Tsimane' oral tradition, landscape, and identity in tropical forest. La Paz: Wagui.

$\rightarrow$ Izquierdo, C. 2005. When "health" is not enough: societal, individual and biomedical assessments of well-being among the Matsigenka of the Peruvian Amazon. Social Science \& Medicine 61:767-783.

$\rightarrow$ Keller, M., B. Fredrickson, O. Ybarra, S. Côté, K. Johnson, J. Mikels, and T. Wager. 2005. A warm heart and a clear head: the contingent effects of weather on human mood and cognition. Psychological Science 17:724-731.

$\rightarrow$ Leonard, W., K. DeWalt, J. Uquillas, and B. DeWalt. 1993. Ecological correlates of dietary consumption and nutritional status in highland and coastal Ecuador. Ecology of Food \& Nutrition 31:67-85.

$\rightarrow-1994$. Diet and nutritional status among cassava producing agriculturalists of coastal Ecuador. Ecology of Food \& Nutrition 32:113-127.

$\rightarrow$ Leonard, W., and R. Godoy. 2008. Tsimane' Amazonian Pane $\rightarrow$ Study (TAPS): the first five years (2002-2006) available to the public in 2008. Economics and Human Biology 6: 299-301.

Lohman, T., A. Roche, and R. Martorell. 1988. Anthropo metric standardization reference manual (abridged edition). Windsor, Ontario: Human Kinetics.

London, M., and B. Kelly. 2007. The last forest: the Amazon in the age of globalization. New York: Random House.

$\rightarrow$ Lu, F. 2007. Integration to market among indigenous peoples. Current Anthropology 48:593-602.

Lunde, T., E. Skoufias, and H. Patrinos. 2007. Indigenous peoples in Latin America: economic opportunities and social networks. Policy Research Working Paper Series 4227. Washington, D.C., World Bank.

Milton, K. 1992. Civilization and its discontents. Natural History 3:37-42.

$\rightarrow$ Murray, C., and L. Chen. 1992. Understanding morbidity change. Population \& Development Review 18:481-503.

Overing, J., and A. Passes, eds. 2007. The anthropology of love and anger: the aesthetics of conviviality in native Amazonia. London: Routledge.

Qureshi, S. 2007. Creating an index to measure food security: identifying the components and determinants and testing usefulness. MA thesis, Sustainable International Development Program, Heller School for Social Policy and Management, Brandeis University, Waltham, MA.

$\rightarrow$ Reeve, M.-E. 1994. Regional interaction in the western Amazon: the early colonial encounter and the Jesuit years, 1538-1767. Ethnohistory 41:106-138.

Reyes-García, V. 2001. Indigenous people, ethnobotanical knowledge, and market economy. A case study of the Tsimane' Amerindians in lowland Bolivia. PhD dissertation, Department of Anthropology, University of Florida, Gainesville, Florida.

$\rightarrow$ Reyes-García, V., V. Vadez, E. Byron, L. Apaza, W. Leonard, E. Perez, and D. Wilkie. 2005. Market economy and the loss of folk knowledge of plant uses: estimates from the Tsimane' of the Bolivian Amazon. Current Anthropology 46:651-656.

$\rightarrow$ Santos, R., and C. Coimbra. 1999. Hardships of contact: enamel hypoplasias in Tupi-Monde Amerindians from the Brazilian Amazonia. American Journal of Physical Anthropology 109:111-127.

Seale, J., S. Shellenberger, C. Rodriguez, J. Seale, and M. Alvarado. 2003. Alcohol use and cultural change in an indigenous population: a case study from Venezuela. Alcohol \& Alcoholism 37:603-608.

Shepard, G. 2002. Three days for weeping: dreams, emotions, and death in the Peruvian Amazon. Medical Anthropology Quarterly 16:200-229.

Stanfield, M. 1998. Red rubber, bleeding trees: violence, slavery, and empire in northwest Amazonia, 1850-1933. Albuquerque: University of New Mexico Press.

$\rightarrow$ Tavares, E., J. Vieira, A. Andriolo, A. Sanudo, S. Gimeno, and I. Franco. 2003. Metabolic profile and cardiovascular risk patterns of an Indian tribe living in the Amazon region of Brazil. Human Biology 75:31-46.

$\rightarrow$ Vadez, V., V. Reyes-García, R. Godoy, L. Apaza, E. Byron, T. Huanca, W. Leonard, D. Wilkie, and E. Perez. 2004. Does integration to the market threaten agricultural diversity? panel and cross-sectional evidence from a horticulturalforaging society in the Bolivian Amazon. Human Ecology 32:635-646. 